\title{
Role of bedside-focused ultrasonographic evaluation in the critical patient: a case report
}

\author{
Andrea Bruzzone, Irene Ponassi, Caterina Passalia, Eleonora Arboscello, Riccardo Ghio
}

Clinica Medica III, Dipartimento di Medicina Interna, Ospedale San Martino e Cliniche Universitarie convenzionate, Genova

\section{ABSTRACT}

We present the case report of an 80 years old woman with late posttraumatic (of low intensity without any immediate clinical alteration) onset of dysphnoea, chest pain and hypotension, in which bedside ultrasonography has been a very useful tool in immediate diagnostic definition (acute respiratory distress syndrome - ARDS due to multiple pulmonary contusions), considering and excluding all possible alternative diagnosis with the same clinical presenta- tion, but also providing a "real time" evaluation of therapeutic regimen (hypovolemia versus excessive fluid embalance) and, last but not least, the chance to perform a close follow up of the ultrasonographic alterations (pleural effusion, signs of alveolar consolidation) pointed out at initial diagnosis. Moreworthly, it has been possible to identify the previous mentioned lesion before they had become evident to standard X-Ray chest evaluation.

\section{SINTESI}

Presentiamo il caso clinico di una donna di 80 anni che, in seguito ad un trauma di intensità lieve senza ripercussioni cliniche avvenuto qualche giorno addietro, presentava dispnea, dolore toracico ed ipotensione; l'ecografia eseguita "al letto" ha costitutito uno strumento molto utile nel conseguire una definizione diagnostica pressoché immediata (sindrome ARDS dovuta a contusioni polmonari), considerando ed escludendo nel contempo tutte le possibili diagnosi alternative con la mede-

\section{Introduction}

Bedside-focused ultrasonographic evaluation is a very useful tool, in addition to clinical examination, in order to define critical conditions eligible for a rapid diagnostic definition and an intensive therapeutic approach; herein we present a case report in which the coexistence of signs and symptoms common to different pathological conditions leads us to formulate multiple diagnostic hypotheses and to quickly resolve them with the aim of bedside-focused ultrasonography evaluation.

\section{Case report}

An 80-year-old caucasian woman was admitted to our hospital because of progressive dysphnea and rapid onset of chest pain - defined by "borderline" features suggestive of acute coronary syndrome ${ }^{1}-$ but absent of fever, cough and any other sympthoms. Her past medical history was unremarkable except for chronic haemodinamically stable atrial fibrillation not requiring antiarrhythmic drugs but treated with anticoagulant therapy. She referred of recent left thoracic trauma five days before and presented signs of wall thoracic ecchimosis. Upon clinical examination, airflow was adequate but she presented severe hypotension $(80 / 50 \mathrm{mmHg})$, heart rate $110 / \mathrm{min}$, Glascow Coma Scale 15/15, and dysphnea (respiratory rate 32/ min, $\mathrm{SO}_{2} 80 \%$ with $\mathrm{FiO}_{2}$ 0.21). Clinical, rectal and neurological examinations were normal without any evidence of gastrointestinal blood loss. Axillary temperature was $36.5^{\circ} \mathrm{C}$, while her electrocardiogram revealed atrial fibrillation with normal ventricular rate and morphology. An arterial blood gas specimen (performed with Radiometer-ABL) revealed $\mathrm{pH} 7.35, \mathrm{PO}_{2} 35 \mathrm{mmHg}$, $\mathrm{PCO}_{2} 48 \mathrm{mmHg}, \mathrm{HCO}_{3} 25 \mathrm{mEq} / \mathrm{l}$ with calculated $\mathrm{PaO}_{2} / \mathrm{FiO}_{2}=$ 166 (with haemoglobin $9.0 \mathrm{mg} / \mathrm{dl}$ and lactate $2.6 \mathrm{mmol} / \mathrm{l}$ ). Chest $\mathrm{X}$-Ray examination did not detect any pathological findings in the lungs and ribs. Clinical suspicion of pulmonary embolism was unlikely according to Well's Score and Ginevra score. sima presentazione clinica; è stata possibile inoltre una valutazione in tempo reale dell'efficacia della terapia (ipovolemia versus sovraccarico volemico) e non ultimo per importanza, è stato eseguito un attento monitoraggio delle alterazioni ecografiche (versamento pleurico, segni di consolidamento polmonare) evidenziati alla diagnosi iniziale. Inoltre abbiamo rilevato che l'identificazione delle lesioni sopra menzionate è stato più precoce rispetto alla radiografia del torace standard.

Reservoir 100\% oxygen supply and fluid challenge with normal isotonic saline at a rate of $250 \mathrm{ml} / 30$ minutes were started and a vescical catetherism was performed in order to monitor diuresis. Awaiting emocromocitometric and other clinical biochemical examinations, we performed bedside-focused emergency ultrasonography evaluation. Lack of collapse of inferior vena cava with inspiration ruled out a hypovolemic condition (Figures 1 and 2), the presence of free peritoneal fluid was excluded, while cardiac transtoracic exploration of the heart excluded acute left ventricular failure, cardiac tamponade and acute right ventricular dilatation due to severe pulmonary hypertension; chest ultrasonography detected a non-omogeneus pattern of multiple Blines arising from the pleural line, mostly in the left emithorax, with confluent consolidations zone and the presence of focal signs of parenchymal distruption with localized pleural effusion

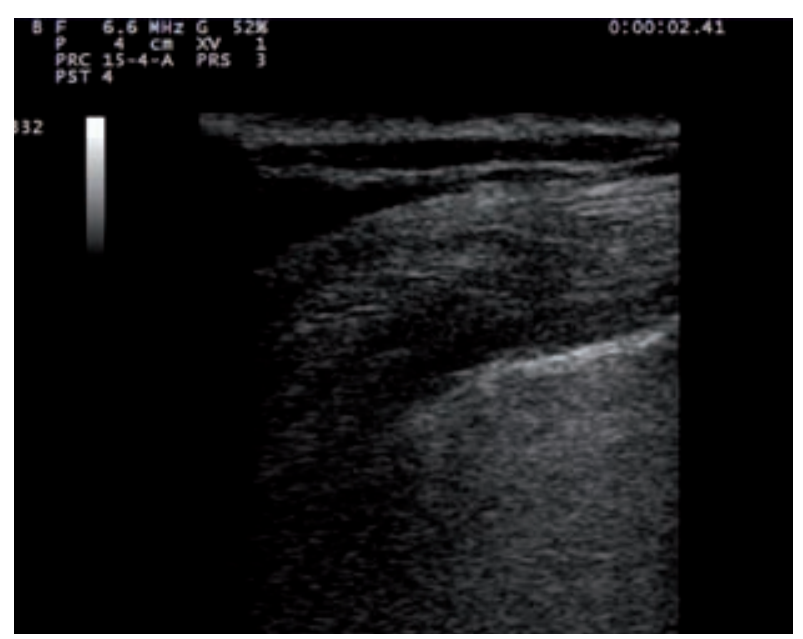

Fig. 1 - Ultrasonography at admission. 


\section{clinica e terapia}

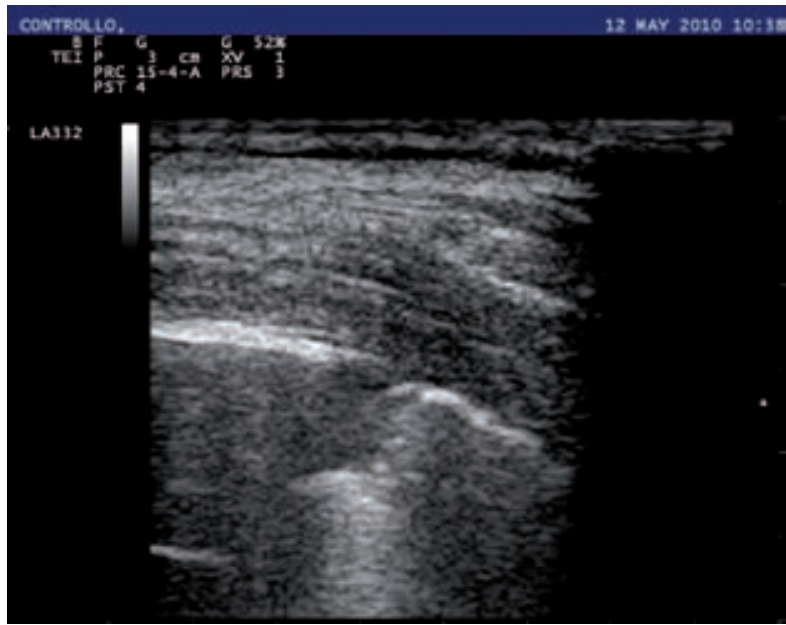

Fig. 2 - Ultrasonography after three days.

(Figures 3, 4 and 5), which is a picture of classic alveolar-interstitial syndrome pattern according to applying classic guidelines $^{2}$, while an alternative diagnosis of cardiogenic pulmonary edema, pneumothorax, pericardial tamponade and pulmonary embolism was excluded.

Hematologic and chemistry laboratory values were: Ht 29,5\%, Hb $92 \mathrm{~g} /$, white cell count $14,000 / \mathrm{mm}^{3}$, neutrophilis $12,700 / \mathrm{mm}^{3}$, platelet count $133,000 / \mathrm{mm}^{3}$, INR 2.45 , fibrinogen $2.75 \mathrm{~g} / \mathrm{l}$, D-Dimer $142 \mu \mathrm{g} / \mathrm{ml}$, total bilirubin $1,32 \mathrm{mg} / \mathrm{dl}$, direct bilirubin $0,3 \mathrm{mg} /$ dl, albumin 2.9 g/l, ferritin 45 mg/dl, CRP 11 mg/l. Conventional I-troponin monitoring was normal as well as myoglobin (Table 1). The main diagnostic hypothesis was consistent with "acute respiratory distress syndrome" (ARDS) secondary to a pulmonary contusion. Therefore the diagnosis was confirmed by a thorax and abdominal contrasted-enhanced computed tomography
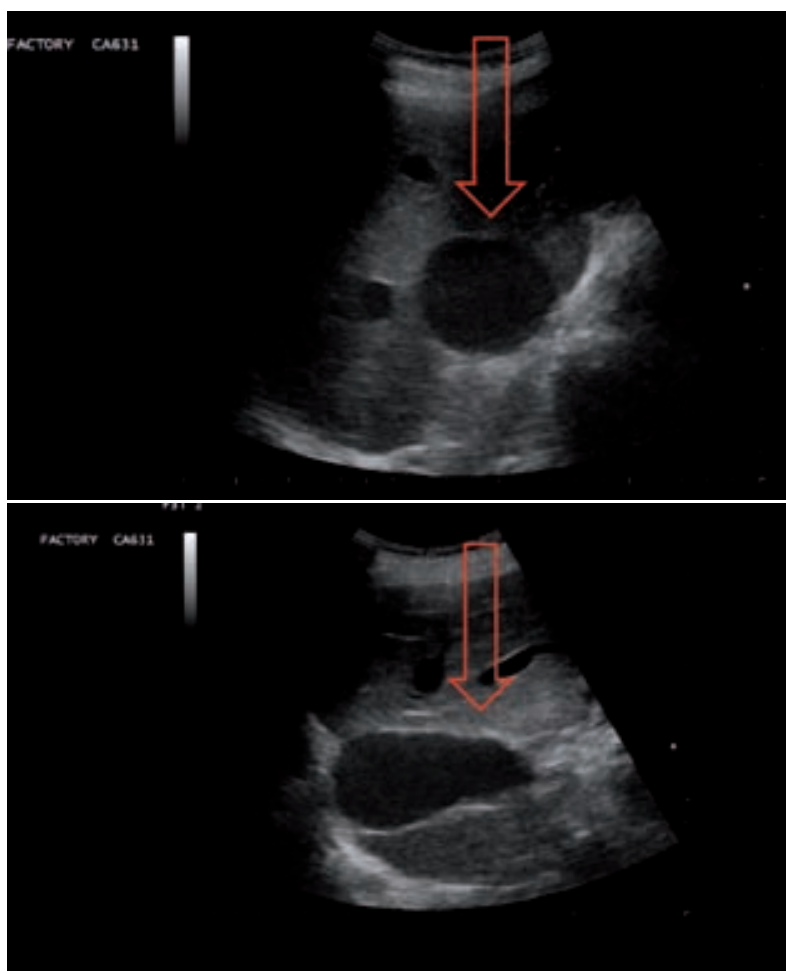

Fig. 3, 4 - A dilatated IVC (IVC diameter $>20 \mathrm{~mm}$ ) roules out hypovolemia; IVC is measured in the sub-xiphiod space in the long and trasversal axis, using the liver as a sonographic window.
Table 1

Hematologic and chemistry laboratory values.

\begin{tabular}{|l|l|l|l|}
\hline & Admission & III day & $\begin{array}{l}\text { 2 weeks } \\
\text { after }\end{array}$ \\
\hline $\mathrm{Hb}(\mathrm{g} / \mathrm{l})$ & 92 & 60 & $\mathrm{I} 04$ \\
\hline $\mathrm{MCV}(\mathrm{fl})$ & $7 \mathrm{I}$ & 76 & 78 \\
\hline White cell (per $\mathrm{mm})$ & $\mathrm{I} 4000$ & 2800 & 9600 \\
\hline Platelet count (per $\mathrm{mm})$ & $\mathrm{I} 33000$ & 80000 & 204000 \\
\hline Fibrinogen $(\mathrm{g} / \mathrm{l})$ & 2,75 & 3,93 & 3,2 \\
\hline Total bilirubin $(\mathrm{mg} / \mathrm{dl})$ & $\mathrm{I}, 32$ & $\mathrm{I}, 34$ & 0,98 \\
\hline
\end{tabular}

scan, which revealed minimal bilateral pleural effusion with multiple parenchimal infiltrates compatible with post-contusive consolidations and hematoma of thoracic wall.

A serious anemia and thromocytopenia have subsequently there occurred due to excessive platelet consumption, thus the patient received transfusion with two packed red cell units.

The ultrasosnographic findings described above underwent to close follow up and correlation with clinical condition and therapy's adjustement:

- After first three days of fluid therapy at rate of $60-80 \mathrm{ml} / \mathrm{h}$ un-
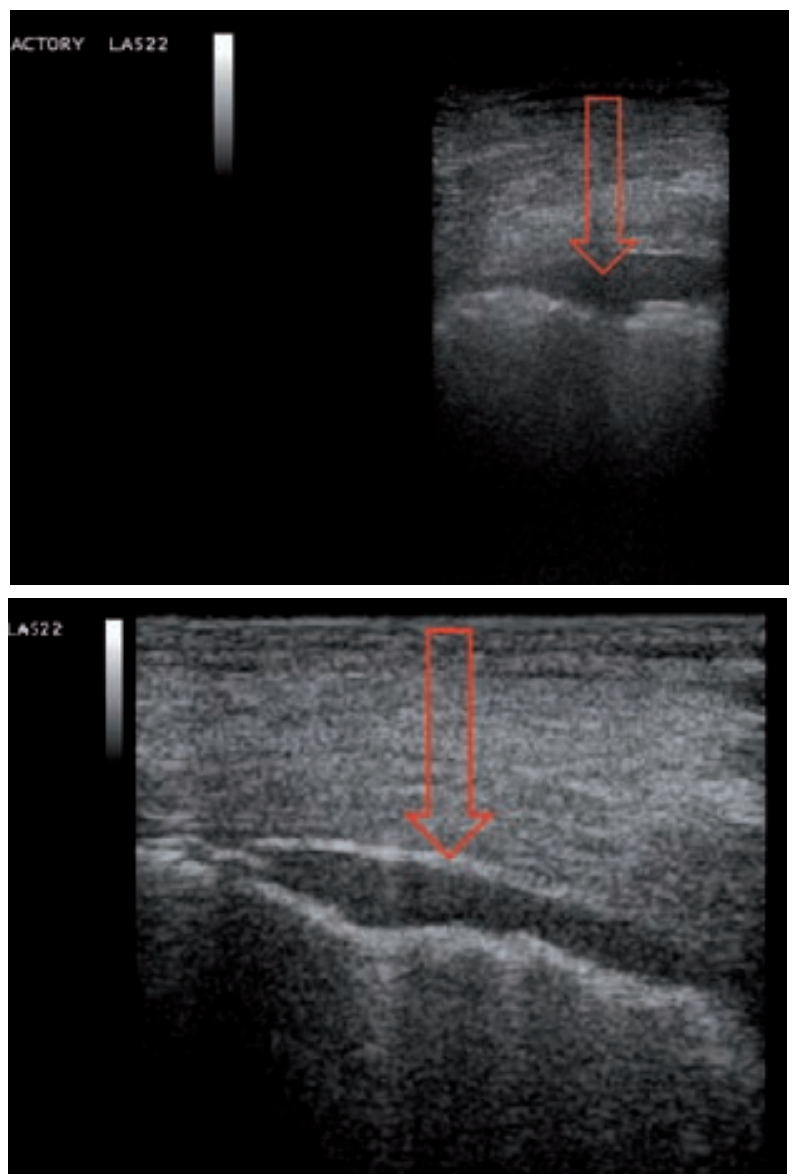

Fig. 5, 6 - Ultrasonographic pattern of parenchymal lung consolidation; hypoechoic subpleural focal images with or without pleural line gap, either isolated or multiple, appear as hypoechoic pleural-based focal images allowing ultrasound transmission, from which B-line-like artifacts arise, with confluent consolidations ("hepatization"). 
Table 2

Aetiological classification of main causes of shock.

\begin{tabular}{|l|l|}
\hline Low cardiac output & High cardiac output \\
\hline Hypovolemic & Septic \\
\hline Cardiogenic & Anaphylactic \\
\hline Extra-cardiac obstructive & Neurogenic \\
\hline
\end{tabular}

Table 3

Diagnostic tools with comparison in rapidity of execution and availability referring to most common clinical abnormalities.

\begin{tabular}{|c|c|c|c|}
\hline Condition & Test & Rapid & Available \\
\hline \multicolumn{4}{|l|}{ Hypovolemic } \\
\hline \multirow[t]{2}{*}{$\begin{array}{l}\text { - Gastrointestinal } \\
\text { bleeding }\end{array}$} & $\begin{array}{l}\text { Upper: NGT } \\
\text { Lower: DRE }\end{array}$ & +++ & +++ \\
\hline & Endoscopic & + & + \\
\hline \multirow{2}{*}{$\begin{array}{l}\text { - Peritoneal bleeding/ } \\
\text { AAA }\end{array}$} & Focused-US & +++ & $+/++$ \\
\hline & CE-CT & $+/++$ & ++ \\
\hline - CVP low & Focused-US & +++ & $+/++$ \\
\hline \multicolumn{4}{|l|}{ Cardiogenic } \\
\hline \multirow[t]{3}{*}{$\cdot \mathrm{ACS}$} & ECG & +++ & +++ \\
\hline & I-troponin & + & +++ \\
\hline & Copeptin & +++ & $?$ \\
\hline $\begin{array}{l}\text { - Structural hearth } \\
\text { disease }\end{array}$ & Focused-US & +++ & $+/++$ \\
\hline - Rhythm disturbance & ECG & +++ & +++ \\
\hline $\begin{array}{l}\text { - Aortic dissection/ } \\
\text { rupture }\end{array}$ & CE-CT & $+/++$ & ++ \\
\hline \multicolumn{4}{|l|}{ Extra-cardiac obstructive } \\
\hline \multirow[t]{2}{*}{ - Pneumothorax } & $R X$ & ++ & +++ \\
\hline & Focused-US & +++ & $+/++$ \\
\hline \multirow[t]{2}{*}{ - Pleural effusion } & $R X$ & ++ & +++ \\
\hline & Focused-US & +++ & $+/++$ \\
\hline - Cardiac tamponade & Focused-US & +++ & $+/++$ \\
\hline \multirow[t]{2}{*}{ - Pulmonary embolism } & CE-CT & $+/++$ & ++ \\
\hline & Focused-US & +++ & $+/++$ \\
\hline \multicolumn{4}{|c|}{$\begin{array}{l}\text { "Not validated yet. } \\
\text { * Can exclude pulmonary embolism with emodinamical instability } \\
\text { - useful for DVT. }\end{array}$} \\
\hline
\end{tabular}

til normalization of blood pressure, we could assist to a progressive lost of inspiratory inferior vena cava collapse (CVP exstimated $15-20 \mathrm{mmHg}$ ) with appearance of right lung Blines; so diuretic therapy was started and anemia (also due to emodiluition) was corrected.

- In entire course of follow up no signs of left ventricular failure or pericardial effusion or free abdominal fluid were evident.

- Lung B-lines became less evident after four days from admis-

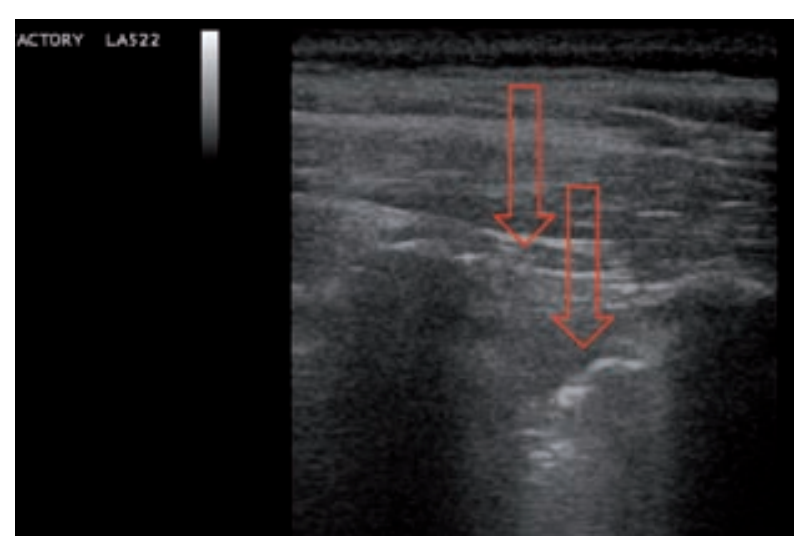

Fig. 7 - The presence of parenchymal disruption with localized pleural effusion.

sion and extinguish at right lung after six days and at left lung after eight days.

- Signs of alveolar consolidation begun to decrease after five days and were not relievable after eleven days, while pleural effusion was not reliable after seventeen days (outward follow up visit).

Our patient was treated furthermore with oxygen, broad-spectrum antibiotics, low-molecular weight heparin (after suspension of dicumarolic therapy) and diuretics, obtaining a clinical and radiological remission in two weeks.

With close ultrasonography monitoring it has been possible to "titrate" fluid and diuretic therapy according to haemodinamic conditions, in particular after three-five days of admission. Also use of anticoagulant therapy (low molecular weight heparin) was safer because of the faculty of exclude free blood loss at any time. Signs of alveolar consolidation became progressively less evident with course of antibiotic therapy(Figure 6), while resolution of "reactive" pleural effusion was slower.

\section{Discussion}

Rapid diagnosis and management of critical patients is strategic in the Emergency Department but hard in cases of unusual presentation or clinical abnormalities common to different pathologic conditions ${ }^{2-5}$. In our case report, careful anamnestic record, accurate physical examination and a few diagnostic tools - with the support of bedside-focused ultrasonography - allowed rapid diagnosis and effective treatment.

The reliability of bedside-focused ultrasonographic evaluation of the chest in the critical patient is demonstrated by the study in BLUE' .

Dyspnea with chest pain and hypotension generally indicates

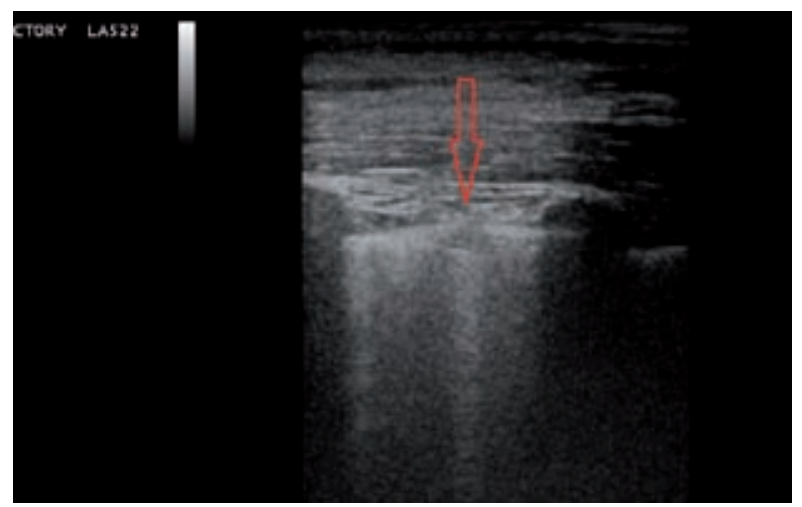

Fig. 8 - Ultrasound control showes size reduction of lesion. 
shock due to low cardiac output (Table 2) and suggestive for hypovolemic (bleeding), cardiogenic (acute coronary syndrome or acute vascular injury), or extra-cardiac obstructive (occupation of pleural space, acute cardiac tamponade, massive pulmonary embolism) conditions.

While the use of a "pre-test probability" scoring system could rule out some pathological conditions (such as pulmonary embolism), the anamnestic recording of chest trauma and anticoagulant therapy associated with a normal ECG and the findings of moderate anemia and acute respiratory failure oriented our diagnostic pathway to a hypovolemic-post traumatic or pleuropulmonary acute condition (such as pneumothorax or emothorax or acute cardio-vascular rupture), despite a clinical cardiopulmonary examination without relevant pathologic findings (such as pleural effusion).

Rapidly performed bedside ultrasonography could easily exclude all pathological hypotheses listed above, thus confirming our diagnosis of ARDS secondary to pulmonary contusion ${ }^{7-9}$. In the Table 3 we list the most appropriate diagnostic tools with comparison in rapidity of execution and availability according to our diagnostic hypothesis.

Nowadays, largely standardized step-by-step protocols and guidelines assist every Emergency Departments team, in order to "focus on" only some clinical and anatomic points of interest, and to make it simple to perform and very reproducible.

FASTCRASH procedure (Focused Assessment Sonography for Trauma, Cardiac failure, Respiratory failure, Acute abdomen and Shock), introduced a few years back, provides rapid clinical and ultrasonographic evaluation of critically ill patients and delivers rapid and reliable results in order to identify the main problems and quickly (less than ten minutes) refer the patient to the most appropriate diagnostic/therapeutic procedure ${ }^{2,9-11}$. Ultrasonographic examination of chest is very useful in an emergency approach of dysphnea/respiratory failure and often provides a more accurate diagnosis of acute cardio-pulmonary disorders compared to standard chest X-Rays; it may be performed at the patient's bed and repeated frequently during follow up, thus avoiding unuseful patient transport and radiological exposition.

With a "targeted approach", recognition of pneumothorax, pleural effusion, parenchimal lung consolidation, diffuse interstitial infiltrates, pulmonary edema and other common conditions becomes very easy and accurate $e^{11-13}$.

\section{Conclusion}

Lung contusion is a frequent clinical entity but often remains undiagnosed - especially upon first evaluation - because a diagnosis is unlikely with a visit and chest radiography $y^{5,7,8}$. Although TC is the gold standard for lung contusion diagnosis, it is expensive and subjects the patient to the risks of transport, contrast agent side effects and radiation and is therefore non-viable for the seriate monitoring of the patient. Various studies have demonstrated that chest ultrasonography can accurately detect lung contusion in blunt trauma victims: sensibility is $94.6 \%$, specificy is $96.1 \%$, positive and negative predictive values are $94.6 \%$ and $96.1 \%$ respectively and accuracy is $95 \%$.

In an emergency situation, a traumatized patient showing signs of shock and acute respiratory deficiency poses a challenge for an ER doctor whose quick and precise diagnosis is needed in order to ensure an effective treatment. Pneumothorax and pleural effusion are accessible to ultrasound; information obtained from lung, cardiac, venous and abdominal analysis provides a bedside visual approach to the critically ill ${ }^{9,14-16}$; according to FASTCRASH method (Focused Abdominal Sonography for Trauma, Cardiac arrest / failure, Respiratory arrest / failure, Acute abdomen and Shock) which constitutes an important tool and leads the intensivist to a more confident management and follow up of critically ill patients ${ }^{3}$.

In our case report, in compresence of thoracic traumatism and possible structural heart disease, it is difficult to distinguish cardiogenic responsibility of haemodynamic alteration and pulmonary direct injury from the responsibility of pain defense in the respiratory distress. Furthermore, in case of arterial hypotension associated, a distinction between hypovolemic form ( iatrogenic or due to internal haemorrhage, especially in patient in anticoagulant therapy) and cardiogenic cause of hypotension itself became crucial.

Disclosures: all authors declare no conflict of interest.

\section{References}

1. American Heart Association. Guidelines ACLS. AHA, Dallas, 2010.

2. Lichtenstein DA, Goldstein I, Mourgeon E et al. Comparative Diagnostic Performances of Auscultation, Chest radiography, and lung ultrasonography in Acute Respiratory Distress Syndrome. Anesthesiology 2004; 100: 9-15.

3. Daniel A. Lichtenstein, MD Ultrasound in the management of thoracic disease. Crit Care Med 2007; 35: 250-261.

4. Tsubo T, Yatsu Y, Suzuki A et al. Daily changes of the area of density in the dependent lung region - evaluation using transesophageal echocardiography. Intensive Care Med 2001; 27:1881-1886

5. Lefcoe MS, Fox GA, Leasa DJ et al. Accuracy of portable chest radiography in the critical care setting. Chest 1994; 105: 885-887.

6. Lichtenstein DA, Mezière GA. Relevance of lung ultrasound in diagnosis of Acute Respiratory Failure; the BLUE protocol. Chest 2008; 134: 117-125.

7. Wyncoll DL, Evans TW. Acute respiratory distress syndrome. Lancet 1999; 354: 497-501.

8. Soldati G, Testa A et al. Chest ultrasonography in lung contusion. Chest 2006; 130: 533-538.

9. Lichtenstein DA, Lascols N, Gilbert Mezire G, Gepner A. Ultrasound diagnosis of alveolar consolidation in the critically ill. Intensive Care Med 2004; 30: 276-281.

10. Melniker LA, Lieibner E, McKenney MG et al. Randomized controlled trial of point-of-care limited ultrasonography (PLUS) for trauma in the e mergency department: the first Sonography Outcomes Assessment Program (SOAP-1) trial. Ann Emerg Med 2006; 48: 227-235.

11. Arbelota C, Ferraria F, Bouhemada B, Rouby J-J. Lung ultrasound in acute respiratory distress syndrome and acute lung injury. Critical Care 2008, 14: 70-74.

12. Gargani F, Frassi G, Soldati P et al. Ultrasound lung comets for the differential diagnosis of acute cardiogenic dyspnoea: a comparison with natriuretic peptide. Eur J Heart Fail 2008; 10: 70-77.

13. Soldati G, Copetti R, Sara Sher S. Sonographic interstitial syndrome. The sound of lung water. J Ultrasound Med 2009; 28: 163-174.

14. Hernandez C, Shuler K, Hannan H, Sonyika C. C.A.U.S.E.: Cardiac arrest ultra-sound exam. A better approach to managing patients in primary non-arrhythmogenic cardiac arrest. Resuscitation 2008; 76: 198-206.

15. Xirouchaki N, Georgopoulos D. The use of lung ultrasound: a brief review for critical care physicians and pneumonologists. Pneumon 2007; 20: 134-141.

16. Copetti R, Soldati G, Copetti P. Chest sonography: a useful tool to differentiate acute cardiogenic pulmonary edema from acute respiratory distress syndrome. Cardiovasc Ultrasound 2008, 6: 16 